\title{
Pulsed Lavage in Cementless Total Hip Arthroplasty Reduces the Incidence of Brooker Grade 3 and 4 Heterotopic Ossifications*
}

\author{
Joris Mellema ${ }^{1}$, Wierd Zijlstra ${ }^{2}$, Tom van Raaij ${ }^{2}$, Basten Have ${ }^{2}$, Jos van Raay ${ }^{2}$ \\ ${ }^{1}$ Department of Surgery, Isala klinics, Zwolle, The Netherlands; ${ }^{2}$ Department of Orthopaedic Surgery, Martini Hospital, Groningen, \\ The Netherlands. \\ E-mail: jmellema@yahoo.com
}

Received October $9^{\text {th }}, 2011$; revised November $16^{\text {th }}, 2011$; accepted November $24^{\text {th }}, 2011$.

\begin{abstract}
Heterotopic ossification (HO) may cause pain, and can lead to loss of hip motion after total hip arthroplasty (THA). There is evidence that pulsed lavage may lower the incidence of $H O$ formation. We assessed the effect of pulsed lavage on the incidence of HO in 87 male patients after THA. All patients received an uncemented THA through a posterolateral approach. 39 patients were treated with pulsed lavage (index group) and 48 males were treated without pulsed lavage (historical control group, matched on aetiology, gender, surgical approach and type of prosthesis). Both groups followed the same postoperative treatment regimen. HO severity was scored in both groups according to the Brooker classification by three blinded orthopaedic surgeons one year postoperatively. Good inter-observer agreement (Kappa 0.7 ) for scoring $\mathrm{HO}$ was found. The incidence of $\mathrm{HO}(51 \%)$ in the index group did not differ significantly ( $p=0.53)$ from the control group (58\%). However, the incidence of clinically relevant HO (Brooker grades 3 and 4) was significantly lower $(p=0.04)$ in the index group (3\%) as compared to the control group (17\%). These results suggest a beneficial effect of pulsed lavage on the incidence of severe heterotopic ossification after cementless THA in male patients.
\end{abstract}

Keywords: Heterotopic Ossification, Pulsed Lavage, Total Hip Arthroplasty, Uncemented

\section{Introduction}

Heterotopic ossification (HO) is a well-known complication after total hip arthroplasty (THA). The incidence of HO varies from $8 \%$ to $90 \%$ depending on risk factors and the criteria used [1,2]. A large meta-analysis of 13 randomized trials, involving 4129 individuals treated with Non Steroid Anti Inflammatory Drugs (NSA IDs) after major hip surgery, reported an overall HO incidence of $37 \%$ [3]. Especially advanced stages of HO, Brooker grades 3 and 4, are clinically relevant because of pain and hip function impairment [4-6].

The exact aetiology of $\mathrm{HO}$ remains unclear. Some have suggested that surgical trauma may stimulate primitive mesenchymal cells to differentiate into osteoblastic cells, which form bone [7,8]. Earlier, Lo and Healy [9] found that non-circulating connective tissue cells with fibroblastic features may cause HO. It seems likely that $\mathrm{HO}$ is the result of inappropriate differentiation of pluripotential mesenchymal cells into osteoblastic stem cells.

*Conflict of Interests: None declared
Some risk factors for $\mathrm{HO}$ around the hip have been identified; male gender, a lateral surgical approach, uncemented arthroplasty, HO after contralateral hip arthroplasty and revision surgery $[10,11]$. Several studies reported beneficial effects of post-operative NSA IDs usage [12] and local radiation therapy [13] in preventing HO formation. However, NSAIDs often cause gastrointestinal side effects, and local radiation may generate higher costs, logistic problems, wound healing disorders and introduces the risk of secondary malignnancies.

Pulsed lavage around the hip joint and gluteal muscles may prevent $\mathrm{HO}$ formation by washing out the primitive mesenchymal cells. It is inexpensive and has no known side effects. Only one study on the effect of pulsed lavage has been published and suggested no protective effect on HO formation [1]. In this study, however, all patients received lavage; pulsed or manual with a syringe. Aim of the current study was to determine whether pulsed lavage compared to no lavage resulted in less clinically relevant $\mathrm{HO}$ formation after cementless THA in male patients. 


\section{Materials and Methods}

Between May 2003 and February 2006, 41 consecutive male patients scheduled for cementless THA were included prospectively. All patients underwent cementless THA through a posterolateral approach because of primary hypertrophic coxarthrosis, and received pulsed lavage during the procedure. Two patients were lost to follow-up. The index group of 39 patients was matched (on aetiology, gender, surgical approach, type of prosthesis and time of follow-up) to a historical control group of 48 patients who received a cementless THA without any form of lavage between March 1993 and December 2001. The local medical ethical committee approved the study design. Informed consent was obtained in all patients. The trial was performed in compliance with the Helsinki Declaration. There were no competing interests.

\subsection{Surgical Procedure}

All patients received a unilateral plasma sprayed porous coated titanium alloy cementless total hip prosthesis with a polyethylene liner (Mallory Head ${ }^{\circ}$, Biomet, Warsaw, Indiana, USA) through a standard posterolateral approach. No lavage or irrigation was used in the control group. The index group received pulsed lavage with a total of 1 litre saline at 2 time points; 1:500 mL after implantation of cup and stem with the hip in dislocated position and 2:500 $\mathrm{mL}$ after reposition. Pulsed lavage was performed with the OptiLavage system ${ }^{\circledR}$ (Biomet, Warsaw, Indiana, USA) in and around the joint and gluteal muscles. After surgery a suction drain was used in all patients routinely. According to protocol no NSAIDs were given postoperatively in both groups. The rehabilitation programme was similar for both groups, and consisted of full weight bearing from the first day after surgery.

\subsection{Scoring Procedure}

HO formation was scored using the Brooker classification on standardized supine anteroposterior pelvic radiographs at time of follow-up [14]. Three blinded orthopaedic surgeons scored all radiographs to assess inter-observer variability [5]. The mode of the 3 observers was used as definitive Brooker score when disagreement in $\mathrm{HO}$ rating occurred.

\subsection{Statistical Analysis}

Baseline characteristics of both groups are displayed using descriptive statistics. Differences between groups were tested with Student's T-test or Mann-Whitney Utest in case of non-normal distribution of a parametric variable or non-parametric variable. Inter-observer agree- ment between the 3 observers in scoring of HO formation using the Brooker classification was determined with the kappa statistics. Numbers and percentages of the amount of $\mathrm{HO}$ formation in both groups were calculated. Brooker scores were divided into 2 groups; grades 1 and 2 (clinically irrelevant) and grades 3 and 4 (clinically relevant) [4-6]. Differences between both groups in Brooker grades were tested with the Fischer's Exact test. All analyses were performed with SPSS version 16.0 for Windows (SPSS inc., Chicago, Illinois). A p value $<0.05$ was considered statistically significant.

\section{Results}

Both groups were equal regarding aetiology, gender, surgical approach, type of prosthesis, and time of follow-up. The index group was significantly $(p=0.002)$ older with a mean age of 62 years as compared to the control group mean age of 55 years (Table 1).

Good inter-observer agreement $(\mathrm{K}=0.7)$ for scoring $\mathrm{HO}$ formation according to the Brooker classification was found (Table 2).

Figure 1 shows the distribution of Brooker grades in the index and control group. HO formation was found in 20 out of 39 patients in the index group, and in 28 out of 48 patients in the control group. Total HO incidence percentage (51\% and 58\%, respectively) did not differ significantly ( $p=0.53$ ) between both groups. However, the index group (1 of 39 patients) had significantly ( $\mathrm{p}=$ 0.04) less Brooker grades 3 and $4 \mathrm{HO}$ compared to the control group (8 of 48 patients); $3 \%$ versus $17 \%$, respectively.

Table 1. Baseline characteristics for the index and control group.

\begin{tabular}{ccc}
\hline Group & Index(N=39) & Control (N = 48) \\
\hline Follow up, months (mean, SD) & $12(7)$ & $15(8)$ \\
Age, years (mean, SD) & $62(9)^{\mathrm{a}}$ & $55(10)^{\mathrm{a}}$ \\
\hline
\end{tabular}

${ }^{\mathrm{a}} \mathrm{p}=0.002$

Table 2. Inter-observer variability for scoring HO formation (Brooker classification).

\begin{tabular}{cc}
\hline Observer combination & к coefficient \\
\hline O1-O2 & 0.779 \\
O1-O3 & 0.654 \\
O2-O3 & 0.734 \\
Average & 0.722 \\
\hline
\end{tabular}




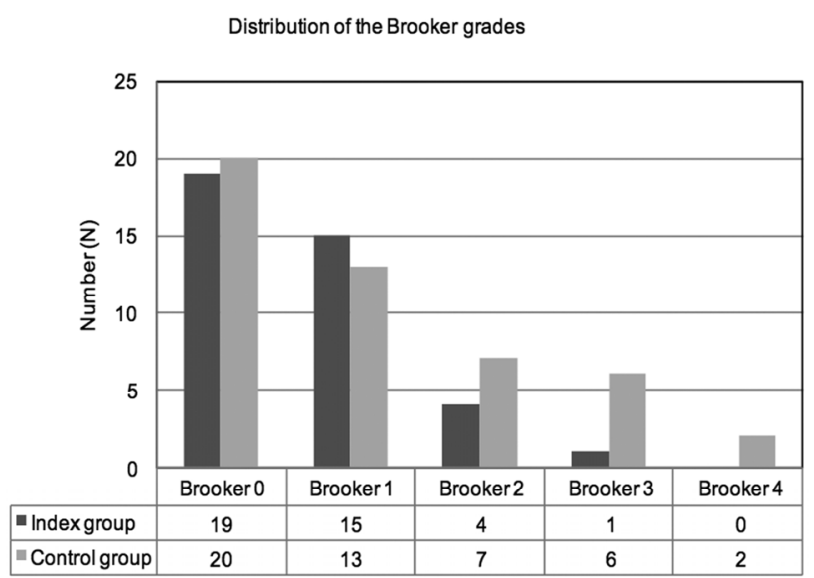

Figure 1. Distribution of the Brooker grades between the index and control groups.

\section{Discussion}

Our results demonstrated significantly less severe HO formation (Brooker grades 3 and 4) with the use of pulsed lavage in male patients treated for symptomatic primary hypertrophic coxarthrosis with uncemented THA. Given the large variation in HO incidence from $8 \%-90 \%$ across different trials [1,2], and the use of a historical control group, rather than a randomised study, we consider that the low numbers compared at Brooker grade 3 \& 4 could lead to misleading conclusions. The present study was limited that patients were not randomized, which may prevent correction for unknown confounding factors that may affect formation of heterotopic bone. Secondly, although our population was homogeneous with respect to gender, aetiology, type of prosthesis, surgical approach, and rehabilitation protocol, the index group was significantly older. Advanced age at surgery is a risk factor for HO after THA [15]. This would suggest that the effect of pulsed lavage is even greater than our results have shown. Thirdly, we only used a radiological outcome at one-year follow-up and no clinical scores were assessed. However, several studies have shown that radiological Brooker grades 3 and 4 correlate positively with clinically relevant $\mathrm{HO}$ formation [4-6]. Also a follow-up of one year seems appropriate because HO will be evident and stable in size at 6 weeks postoperatively, while maturation of formed HO takes place up to 6 months after surgery [16].

A wide range (8\% - 90\%) in HO incidence after THA has been described.[1,11,15] These differences may depend on the reliability of the HO classification system used. Different systems have been suggested for assessing $\mathrm{HO}$ formation. Toom et al. [17] reported high inter-observer reliability for three methods assessing $\mathrm{HO}$ formation (Arcq ( $k=0.9)$ [18] DeLee $(k=0.9)$ [19] and
Della Valla $(k=0.9)$ [5]). We used the widely accepted and most frequently used Brooker's classification [20]. A recent study showed good inter-observer agreement $(\mathrm{k}=$ 0.8 ) for assessing $\mathrm{HO}$ formation with the Brooker's classification [17]. We also found good inter-observer agreement $(\mathrm{k}=0.7)$ between three experienced blinded orthopaedic surgeons for scoring HO on standard anteroposterior pelvic radiographs. More likely, heterogeneity among studies contributes to the various incidences of $\mathrm{HO}$ reported. A recent report on 134 patients who had a cementless hydroxyapatite-coated THA without pharmacologic or radiotherapeutic prophylaxis, showed $67 \% \mathrm{HO}$ formation [21]. While another randomized study reported $31 \%$ HO formation in 97 patients treated with uncemented total hip arthroplasty [22]. A systematic overview of 201 studies showed the incidence of any heterotopic bone formation to be $43 \%$ after total hip replacement, the incidence of severe HO was $9 \%$. Information about patient characteristics, use of heterotopic bone formation prophylaxis, other NSAID use and details of surgery and follow up were very incompletely reported and generally available for less than one-quarter of the included studies [20]. Risk factors for HO have been recognized and include male sex, posterolateral approach and hypertrophic osteoarthritis [10,11]. Our study population was selected for these known risk factors, and $\mathrm{HO}$ formation was found in $51 \%$ of the cases in the index group versus $58 \%$ in the control group.

The incidence of clinically relevant $\mathrm{HO}$ was $3 \%$ in the index group versus $17 \%$ in the control group, which was significantly $(p=0.04)$ different. This suggests a beneficial effect on severe HO formation by using pulsed lavage. The exact aetiology of $\mathrm{HO}$ formation is still unknown. Some have suggested that mesenchymal pluripotential stem cell release from bone during surgery may act as a stimulus [23,24]. McCarthy proposed a chain of events in which four factors are important: surgical trauma that leads to haematoma; protein messengers release from traumatized cells or inflammatory cells that arrive at the location of trauma; protein messengers activation of mesenchymal cells to transform into osteoblasts or chondroblasts, and a proper environmental condition that enables HO formation [8]. Pulsed lavage may have the potential to washout mesenchymal pluripotential stem cells and messenger proteins, or to distort the proper environmental condition needed for HO formation. Clinical studies on the effect of pulsed lavage in THA treatment are rare, and only one study reported on pulsed lavage and HO formation [1]. This small and heterogeneous study found no positive effect for pulsed over syringe lavage, but lacked a true control group which had no lavage at all. A recent Japanese trial on 1000 uncemented THA's through a posterolateral approach reported severe 
HO formation in only $1 \%$ of the cases. A large portion of patients (40\%) received NSAIDs postoperatively, and all wounds were irrigated with $1000 \mathrm{~mL}$ of saline [25]. Although no pulsatile lavage was used wound lavage may have had an additional beneficial effect, causing the low incidence of $\mathrm{HO}$.

\section{Conclusions}

In conclusion our study showed significantly less Brooker grades 3 and 4 heterotopic ossifications after cementless THA in male patients treated with pulsed lavage. This suggests a positive effect of pulsed lavage on preventing clinically relevant $\mathrm{HO}$ formation. Other studies suggested that lavage in general reduces the incidence of $\mathrm{HO}$ after THA. Future prospective randomized trials should elucidate whether pulsed lavage, in addition to syringe lavage and no lavage at all, is superior.

\section{Acknowledgements}

We thank I. van de Akker-Scheek, PhD, for her contribution to the manuscript.

\section{REFERENCES}

[1] R. J. Sneath, F. D. Bindi, J. Davies and E. J. Parnell, “The Effect of Pulsed Irrigation on the Incidence of Heterotopic Ossification after Total Hip Arthroplasty,” Journal of Arthroplasty, Vol. 16, No. 5, 2001, pp. 547-551. doi:10.1054/arth.2001.23562

[2] A. Toom, T. Haviko and L. Rips, "Heterotopic Ossification after Total Hip Arthroplasty," International Orthopaedics, Vol. 24, No. 6, 2001, pp. 323-326. doi:10.1007/s002640000181

[3] B. C. Neal, A. Rodgers, T. Clark, H. Gray, I. R. Reid, L. Dunn, et al., "A Systematic Survey of 13 Randomized Trials of Non-Steroidal Anti-Inflammatory Drugs for the Prevention of Heterotopic Bone Formation after Major Hip Surgery,” Acta Orthopaedica, Vol. 71, No. 2, 2000, 122-128. doi:10.1080/000164700317413076

[4] A. Buvanendran, J. S. Kroin and R. A. Berger, "Preoperative Cyc-Looxygenase-2 Inhibitor Treatment Reduces the Incidence of Hheterotopic Ossification after Hip Arthroplasty: Six-Month Follow-Up,” Anesthesiology, Vol. 107, No. 2, 2007, 358-359.

doi:10.1097/01.anes.0000271873.86164.74

[5] A. G. Della-Valle, P. S. Ruzo, V. Pavone, E. Tolo, D. N. Mintz and E. A. Salvati, "Heterotopic Ossification after Total Hip Arthro-Plasty: A Critical Analysis of the Brooker Classification and Proposal of a Simplified Rating System,” Journal of Arthroplasty, Vol. 17, No. 7, 2002, 870-875.

[6] P. Kjaersgaard-Andersen and M. A. Ritter, "Prevention of Formation of Heterotopic Bone after Total Hip Arthroplasty," Journal of Bone and Joint Surgery, Vol. 73, No.

\section{6, 1991, 942-947.}

[7] O. Kolbl, D. Knelles, T. Barthel, U. Kraus, M. Flentje and J. Eulert, "Randomized Trial Comparing Early Postoperative Irradiation vs. the Use of Nonsteroidal Antiinflammatory Drugs for Prevention of Heterotopic Ossification Following Prosthetic Total Hip Replacement,” International Journal of Radiation Oncology, Biology and Physics, Vol. 39, No. 5, 1997, pp. 961-966. doi:10.1016/S0360-3016(97)00496-3

[8] E. F. McCarthy and M. Sundaram, "Heterotopic Ossification: A Review,” Skeletal Radiology, Vol. 34, No. 10, 2005, pp. 609-619. doi:10.1007/s00256-005-0958-z

[9] T. C. Lo and W. L. Healy, "Re-Irradiation for Prophylaxis of Heterotopic Ossification after Hip Surgery,” British Journal of Radiology, Vol. 74, No. 882, 2001, pp. 503506.

[10] B. R. Horwitz, N. L. Rockowitz, S. R. Goll, R. E. Booth, Jr., R. A. Balderston, R. H. Rothman, et al., "A Prospective Randomized Comparison of Two Surgical Approaches to Total Hip Arthroplasty," Clinical Orthopaedics and Related Research, Vol. 291, 1993, pp. 154-163.

[11] J. G. Nollen and F. Q. van Douveren, "Ectopic Ossification in Hip Arthroplasty. A Retrospective Study of Predisposing Factors in 637 Cases," Acta Orthopaedica, Vol. 64, No. 2, 1993, pp. 185-187. doi:10.3109/17453679308994567

[12] K. Knahr, M. Salzer, R. Eyb, P. Frank and W. Blauensteiner, "Heterotopic Ossification with Total Hip Endoprostheses in Various Models of Thrombosis Prophylaxis,” Journal of Arthroplasty, Vol. 3, No. 1, 1988, pp. 1-8. doi:10.1016/S0883-5403(88)80047-0

[13] D. C. Ayers, C. M. Evarts and J. R. Parkinson, "The Prevention of Heterotopic Ossification in High-Risk Patients by Low-Dose Radiation Therapy after Total Hip Arthroplasty,” Journal of Bone and Joint Surgery, Vol. 68, No. 9, 1986, pp. 1423-1430.

[14] A. F. Brooker, J. W. Bowerman, R. A. Robinson, L. H. Riley Jr., "Ectopic Ossification Following Total Hip Replacement. Incidence and a Method of Classification," Journal of Bone and Joint Surgery, Vol. 55, No. 8, 1973, pp. 1629-1632.

[15] P. Kjaersgaard-Andersen, J. Sletgard, C. Gjerloff and F. Lund, "Heterotopic Bone Formation after Noncemented Total Hip Arthroplasty. Location of Ectopic Bone and the Influence of Postoperative Antiinflammatory Treatment," Clinical Orthopaedics and Related Research, Vol. 252, 1990, pp. 156-162.

[16] M. A. Ritter and R. B. Vaughan, "Ectopic Ossification after Total Hip Arthroplasty. Predisposing Factors, Frequency, and Effect on Results,” Journal of Bone and Joint Surgery, Vol. 59, No. 3, 1977, pp. 345-351.

[17] A. Toom, K. Fischer, A. Martson, L. Rips and T. Haviko, "Inter-Observer Reliability in the Assessment of Heterotopic Ossification: Proposal of a Combined Classification,” International Orthopaedics, Vol. 29, No. 3, 2005, pp. 156-159. doi:10.1007/s00264-004-0603-9

[18] M. Arcq, "Die Paraartikulären Ossifikationeneine Kom- 
plikation der Totalhüftendoprothese des Hüftgelenks,” Arch Orthop Unfallchir, Vol. 77, 1973, pp. 108-131. doi:10.1007/BF00416444

[19] J. DeLee, A. Ferrari and J. Charnley, "Ectopic Bone Formation Following Low Friction Arthroplasty of the Hip," Clinical Orthopaedics and Related Research, Vol. 121, 1976, pp. 53-59.

[20] B. Neal, H. Gray, S. MacMahon and L. Dunn, "Incidence of Heterotopic Bone Formation after Major Hip Surgery," ANZ Journal of Surgery, Vol. 72, No. 11, 2002, 808-821. doi:10.1046/j.1445-2197.2002.02549.x

[21] R. J. Kasetti, A. A. Shetty and C. Rand, "Heterotopic Ossification after Uncemented Hydroxyapatite-Coated Primary Total Hip Arthroplasty,” Journal of Arthroplasty, Vol. 16, No. 8, 2001, pp. 1038-1042. doi:10.1054/arth.2001.25550
[22] K. R. Rama, P. A. Vendittoli, M. Ganapathi, R. Borgmann, A. Roy and M. Lavigne, "Heterotopic Ossification after Surface Replacement Arthroplasty and Total Hip Arthroplasty: A Randomized Study," Journal of Arthroplasty, Vol. 24, No. 2, 2009, pp. 256-262. doi:10.1016/j.arth.2007.12.004

[23] J. E. Puzas, C. M. Evarts and J. S. Brand, "The Stimulus for Bone Formation,” Hip, 1987, pp. 25-38.

[24] B. J. Thomas, "Heterotopic Bone Formation after Total Hip Arthroplasty,” Orthopedic Clinics of North America, Vol. 23, No. 2, 1992, pp. 347-358.

[25] T. Higo, M. Mawatari, M. Shigematsu and T. Hotokebuchi, "The Incidence of Heterotopic Ossification after Cementless Total Hip Arthroplasty,” Journal of Arthroplasty, Vol. 21, No. 6, 2006, pp. 852-856. doi:10.1016/j.arth.2005.10.016 